\title{
Benzoylnitrene Radical Anion: A New Reagent for the Generation of $\mathrm{M}-2 \mathrm{H}$ Anions
}

\author{
Neloni R. Wijeratne and Paul G. Wenthold \\ Department of Chemistry, Purdue University, West Lafayette, Indiana, USA
}

Benzoylnitrene radical anion, formed in high abundance by electron ionization of benzoylazide, is found to be a useful reagent for the formation of ionized reactive intermediates, such as diradicals and carbenes. The reactivity of the ion is similar to what is observed with atomic oxygen anion, occurring in many instances by $\mathrm{H}_{2}^{+}$transfer. However, because benzoylnitrene radical anion is less basic than oxygen anion, it undergoes $\mathrm{H}_{2}^{+}$transfer with substrates that react with oxygen anion by only proton transfer and therefore can be used to generate reactive ions not easily prepared by other methodologies. (J Am Soc Mass Spectrom 2007, 18, 2014-2016) (C 2007 American Society for Mass Spectrometry

$\mathrm{T}$ The atomic oxygen anion $\left(\mathrm{O}^{-}\right)$is a versatile reagent that can be used for chemical ionization but has in the last 30 years often been utilized predominately for the generation of negative ions of highly reactive species [1]. Although the reactivity of the ion in the formation of reactive species can be unselective and/or unpredictable, reaction of $\mathrm{O}^{-}$with organic precursors is still the first method of choice for the generation of ionized carbenes or ionized diradicals. Part of the appeal of atomic oxygen ion is that it is readily generated by electron or discharge ionization of either $\mathrm{N}_{2} \mathrm{O}$ or $\mathrm{O}_{2}$, and therefore can be used in almost all chemical ionization sources. In particular, oxygen ion is readily generated in the sources of negative ion photoelectron spectrometers, and therefore ions formed by reaction with $\mathrm{O}^{-}$and their corresponding neutrals can be studied by photoelectron spectroscopy [2].

One of the limitations to the reactivity of $\mathrm{O}^{-}$is that it is relatively basic $\left(\Delta \mathrm{H}_{\text {acid }}(\mathrm{OH})=382.6 \mathrm{kcal} / \mathrm{mol}\right)$ [3] such that reactions with strong acids, such as phenols and carboxylic acids, will occur mostly by proton transfer. As such, $\mathrm{O}^{-}$is generally not well-suited for the generation of oxygen-based $\mathrm{M}-2 \mathrm{H}$ ions. Consequently, more complicated reactivity approaches have been developed to facilitate the synthesis of these types of species. However, these methods are not as general as reaction with $\mathrm{O}^{-}$, and require either specific ion sources [4], specialized reactants [5], or use of hazardous reagents [6].

In the course of recent investigations of nitrenes, we examined the reactivity of benzoylnitrene radical anion, $\mathbf{1}^{-}$[7], in a flowing afterglow-triple quadrupole mass spectrometer, described previously [8,9]. Ion $\mathbf{1}^{-}$is readily formed in very high abundance by 70

Address reprint requests to Dr. P. G. Wenthold, Department of Chemistry, Purdue University, 560 Oval Drive, West Lafayette, IN 47907-1084, USA. E-mail: pgw@purdue.edu
eV electron ionization (EI) of benzoylazide, $\mathbf{1 a}$ (eq 1), a solid reagent easily synthesized [10] by reaction of benzoylchloride with sodium azide. [Azides are potentially explosive and should be handled with proper precautions. However, we have not encountered any problems in this work.] Conditions in the flowing afterglow include $\mathrm{P}(\mathrm{He})=0.400$ torr, with flow $(\mathrm{He})=200 \mathrm{~L} / \mathrm{min}(\mathrm{STP})$. Under EI conditions, other primary ionic products include $\mathrm{NCO}^{-}$and phenide, $\mathrm{C}_{6} \mathrm{H}_{5}{ }^{-}$, formed in 5 and $1 \%$, respectively, of the abundance of $\mathbf{1}^{-}$. A secondary product is also observed with $m / z=224$, which likely corresponds to a product resulting from condensation $\mathbf{1}^{-}$and $\mathbf{1 a}$ accompanied by loss of mass 42, which could be either $\mathrm{N}_{3}$ or $\mathrm{NCO}$. Under normal operating conditions, the abundance of the $m / z 224$ ion is ca. 5\% of that for $\mathbf{1}^{-}$, such that ion $\mathbf{1}^{-}$is overwhelmingly the most abundant ion in the reactor. Collision-induced dissociation of $\mathbf{1}^{-}$occurs by formation of $m / z 42$, which is presumably the isocyanate anion, $\mathrm{NCO}^{-}$. The dissociation threshold for loss of $\mathrm{NCO}^{-}, 0.85 \mathrm{eV}$, [7] rules out other possible structures, such as phenylisocyanate radical anion, which would have a much higher dissociation energy if they were formed $(>1.37 \mathrm{eV})$ [3].

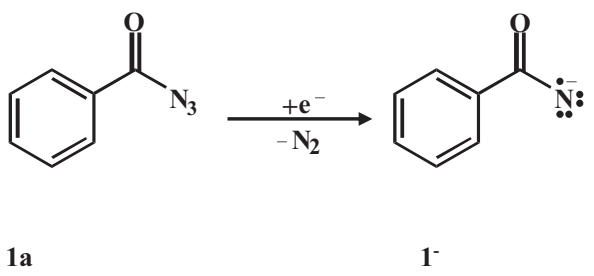

Reaction of $\mathbf{1}^{-}$with phenols occurs by hydrogen atom transfer (HAT), leading to formation of $m / z 120,2$, which 


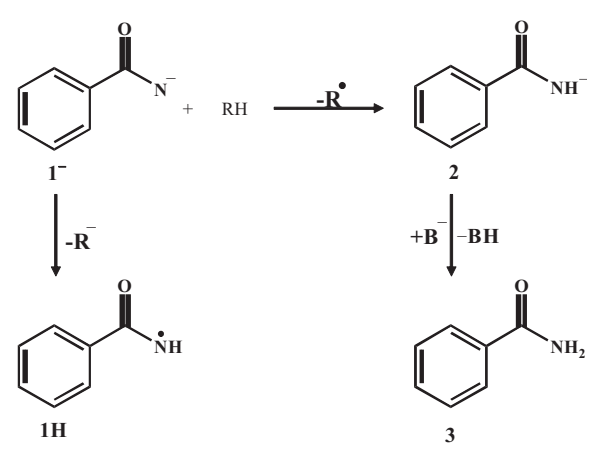

Scheme 1

Table 1. Thermochemical properties of species used in this work (values in $\mathrm{kcal} / \mathrm{mol}$ )

\begin{tabular}{lccl}
\hline \multicolumn{1}{c}{$\mathrm{R}-\mathrm{H}$} & $\Delta \mathrm{H}_{\text {acid }}(\mathrm{R}-\mathrm{H})$ & \multicolumn{1}{c}{$D \mathrm{H}_{298}(\mathrm{R}-\mathrm{H})$} & Reference \\
\hline \hline $\mathrm{C}_{6} \mathrm{H}_{5} \mathrm{CONH}, \mathbf{1 H}$ & $346 \pm 2.1$ & & 7 \\
$\mathrm{C}_{6} \mathrm{H}_{5} \mathrm{CONH}^{-}, \mathbf{2}$ & & $96 \pm 3$ & 7 \\
$\mathrm{C}_{6} \mathrm{H}_{5} \mathrm{CONH}{ }_{2}, \mathbf{3}$ & $354.0 \pm 2.1$ & $104 \pm 4$ & 3,12 \\
$\mathrm{C}_{6} \mathrm{H}_{5} \mathrm{OH}$ & $350 . \pm 2$ & $90 \pm 3$ & 3,14 \\
$\mathrm{C}_{6} \mathrm{H}_{5} \mathrm{CH}_{3}$ & $379.2 \pm 2.1$ & $89 \pm 0.6$ & $3,13,14$ \\
$\mathrm{C}_{6} \mathrm{H}_{5} \mathrm{NH}_{2}$ & $366.4 \pm 2.1$ & $90 \pm 2$ & 3,16 \\
$\mathrm{C}_{6} \mathrm{H}_{5} \mathrm{NH}^{-}$ & $-366.4 \pm 2.1$ & $95 \pm 4$ & 3 \\
$\mathrm{CH}_{3} \mathrm{CO}_{2} \mathrm{H}$ & $348.1 \pm 2.2$ & $112 \pm 3$ & 3,14 \\
\hline
\end{tabular}

is the same ion that is formed by deprotonation of benzamide, 3 (Scheme 1). HAT in these reactions is exothermic, as the hydrogen atom affinity of $\mathbf{1}^{-}$is $96 \mathrm{kcal} / \mathrm{mol}$ (Table 1 ), whereas the $\mathrm{O}-\mathrm{H}$ bond dissociation energies (BDEs) are ca. $90 \mathrm{kcal} / \mathrm{mol}$ in phenols [11, 12]. Although the $\mathrm{C}-\mathrm{H}$ and $\mathrm{N}-\mathrm{H}$ BDEs in toluene and aniline, respectively, are similar to that in phenol [13-16], no reaction is observed between $\mathbf{1}^{-}$and toluene or aniline, indicating that there may be energy barriers to slow these reactions.

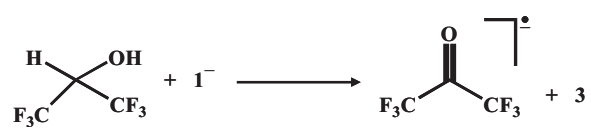

With reagents that contain a second acidic proton, $\mathrm{M}-2 \mathrm{H}$ ions are observed. For example, reaction with 1,1,1,3,3,3-hexafluoro-2-propanol gives efficient formation of $m / z 166$, the hexafluoroketone radical anion (eq 2). High yields of $\mathrm{M}-2 \mathrm{H}$ ions are also observed with methylphenols $(o-, m-$, and $p$-cresol). The resulting ions presumably correspond to previously unobserved quinomethane radical anions, 4. Given that hydrogen abstraction occurs from phenols but not toluene, the reaction likely proceeds first by hydrogen abstraction from oxygen, followed by deprotonation at the $\alpha$-carbon (Scheme 2).

$\mathrm{M}-2 \mathrm{H}$ ions are also observed in reactions of $\mathbf{1}^{-}$with hydroquinones. Thus, reaction of $m$-hydroquinone gives the $m$-quinone radical anion (eq 3) [17]. Although dehydrophenol anions could possibly be formed by deprotonation of ring protons, they can be ruled out by the fact that $\mathrm{M}-2 \mathrm{H}$ anions are not formed in the reaction with phenol. An important feature of the generation of

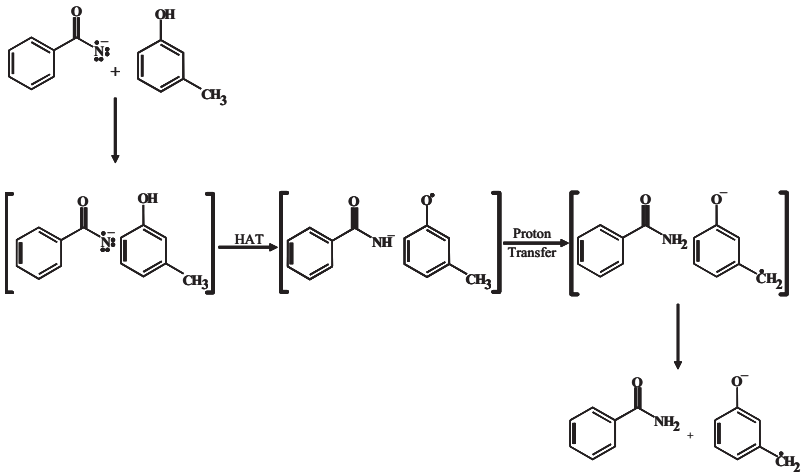

Scheme 2

$\mathrm{M}-2 \mathrm{H}$ ions from phenol derivatives is that the acidity of the conjugate acid radical, $\mathbf{1 H}$, is below those of many phenols (Table 1 ), such that ion $\mathbf{1}^{-}$is typically not basic enough to deprotonate them. As a result, the mass spectrum is not complicated by the presence of a peak at mass (M-1). One exception is the reaction of $\mathbf{1}^{-}$with 2,5-dihydroxy-p-quinone (eq 4), in which deprotonation is about eight times more efficient than $\mathrm{H}_{2}^{+}$abstraction.

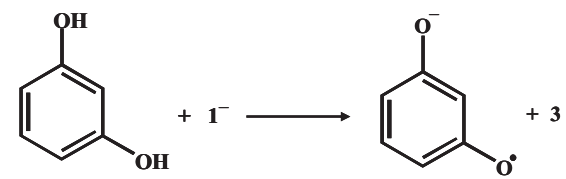<smiles>O=C1C=C(O)C(=O)C(O)=CC1=O</smiles><smiles>Cc1ccccc1Cl</smiles>

(4a)<smiles>Oc1cccc(O)c1</smiles>

(4b)

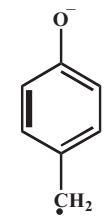

$(4 c)$
However, it is worth noting that the $(\mathrm{M}-2 \mathrm{H})$ ion 5, the negative ion of tetra-oxobenzene, is still formed in the reaction in sufficient yield for subsequent studies. 
Other reagents we have found that give $\mathrm{M}-2 \mathrm{H}$ ions upon reaction with $\mathbf{1}^{-}$include malononitrile (eq 5a), 3-methylbenzoic acid (eq 5b), and acetic acid (eq 5c). The $\mathrm{M}-2 \mathrm{H}$ products are formed in varying yields in absolute terms (due mainly to volatility issues) and relative to the $\mathrm{M}-\mathrm{H}$ ions. With acetic acid, additional reaction products are observed including the HAT product and $\mathrm{CO}_{3}^{-}$, which corresponds to transfer of $\mathrm{O}^{-}$ and loss of methane. An ion corresponding to $\mathrm{CH}_{3} \mathrm{CO}_{2}^{-}$ is also observed in the reaction, but it likely results from reaction between acetic acid and the HAT transfer product, 2 , because $\mathbf{1}^{-}$is not sufficiently basic to deprotonate acetic acid (Table 1 ).
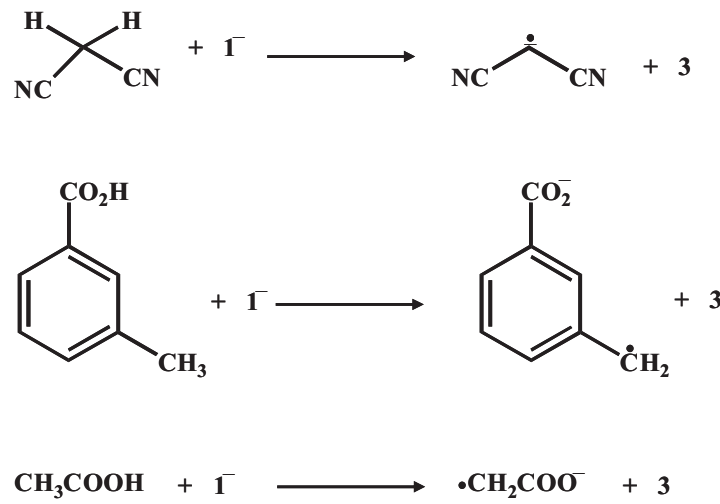

In principle, any $\mathrm{M}-2 \mathrm{H}$ reagent ion could produce $\mathrm{M}-2 \mathrm{H}$ products in ion-molecule reactions. For example, phenylnitrene anion is an $\mathrm{M}-2 \mathrm{H}$ ion that can be readily generated by EI of phenyl azide [18-24]. However, phenylnitrene anion gives poor yields of $\mathrm{M}-2 \mathrm{H}$ ions upon reaction with the substrates listed above, and generally only $\mathrm{M}-\mathrm{H}$ anions are observed. The reactivity can likely be attributed to the higher proton affinity of phenyl nitrene anion $\left(\Delta \mathrm{H}_{\text {acid }}\left(\mathrm{C}_{6} \mathrm{H}_{5} \mathrm{NH}\right)=371 \pm 3\right.$ $\mathrm{kcal} / \mathrm{mol}$ ) [24], causing it to react predominantly by proton transfer. Reactions with less acidic substrates such as acetone, however, do not result in the formation of $(\mathrm{M}-2 \mathrm{H})$ ions.

Benzoylnitrene radical anion is a new reagent for the synthesis of radical anions, including ionized carbenes and diradicals. It is easily generated by electron ionization, and is therefore amenable to a wide range of instrumentation. Although its reactivity is similar to that of $\mathrm{O}^{-}$, it can be used with substrates that are too acidic to give $\mathrm{M}-2 \mathrm{H}$ ions with $\mathrm{O}^{-}$. Therefore, it can be used to generate oxygen-based ions such as ionized quinones and quinomethanes, and the acetate radical.

\section{Acknowledgments}

This work was supported by the National Science Foundation (CHE04-54874). The authors thank the donors of the Petroleum
Research Fund, administered by the American Chemical Society, for partial support of this work.

\section{References}

1. Lee, J.; Grabowski, J. J. Reactions of the Atomic Oxygen Radical Anion and the Synthesis of Organic Reactive Intermediates. Chem. Rev. 1992, 92, 1611-1647.

2. Wenthold, P. G.; Lineberger, W. C. Negative Ion Photoelectron Spectroscopy Studies of Organic Reactive Intermediates. Acc. Chem. Res. 1999, 32, 597-604.

3. Bartmess, J. E. In Negative Ion Energetics Data. NIST Chemistry WebBook, NIST Standard Reference Database Number 69; Linstrom, P. J. Mallard, W. G., Eds.; National Institute of Standards and Technology: Gaithersburg MD, 2005; http:/ / webbook.nist.gov

4. Reed, D. R.; Hare, M.; Kass, S. R. Formation of Gas-Phase Dianions and Distonic Ions as a General Method for the Synthesis of Protected Reactive Intermediates. Energetics of 2,3- and 2,6-Dehydronaphthalene. J. Am. Chem. Soc. 2000, 122, 10689-10696.

5. Zhong, M.; Chabinyc, M. L.; Brauman, J. I. Generation and Chemistry of Fluorinated Acetoxyl and Oxyallyl Biradical Anions (Distonic Radical Anions) in the Gas Phase. J. Am. Chem. Soc. 1996, 118, 12432-12436.

6. Wenthold, P. G.; Hu, J.; Hill, B. T.; Squires, R. R. Gas-Phase Negative Ion Chemistry of Molecular Fluorine. Synthesis of Distonic Radical Anions and Related Species. Int. J. Mass Spectrom. Ion Processes 1998, 179/180, 173-183.

7. Wijeratne,, N. R., Wenthold,, P. G. Thermochemical Studies of Benzoylnitrene Radical Anion: The N-H Bond Dissociation Energy in Benzamide in the Gas Phase, in press.

8. DePuy, C. H.; Bierbaum, V. M.; Flippin, L. A.; Grabowski, J. J.; King, G. K.; Schmitt, R. J.; Sullivan, S. A. Gas-Phase Reactions of Anions with Substituted Silanes. J. Am. Chem. Soc. 1980, 102, 5012-5015.

9. Marinelli, P. J.; Paulino, J. A.; Sunderlin, L. S.; Wenthold, P. G.; Poutsma, J. C.; Squires, R. R. A Tandem Selected Ion Flow Tube-Triple Quadrupole Instrument. Int. J. Mass Spectrom. Ion Processes 1994, 130, 89-105.

10. Liu, J.; Mandel, S.; Hadad, C. M.; Platz, M. S. A Comparison of Acetyland Methoxycarbonylnitrenes by Computational Methods and a Laser Flash Photolysis Study of Benzoylnitrene. J. Org. Chem. 2004, 69, 8583-8593.

11. Angel, L. A.; Ervin, K. M. Gas-Phase Acidities and O-H Bond Dissociation Enthalpies of Phenol, 3-Methylphenol, 2,4,6-Trimethylphenol, and Ethanoic Acid. J. Phys. Chem. A 2006, 110, 10392-10403.

12. Angel, L. A.; Ervin, K. M. Competitive Threshold Collision-Induced Dissociation: Gas-Phase Acidity and O-H Bond Dissociation Enthalpy of Phenol. J. Phys. Chem. A 2004, 108, 8346-8352.

13. Ellison, G. B.; Davico, G. E.; Bierbaum, V. M.; DePuy, C. H. Thermochemistry of the Benzyl and Allyl Radicals and Ions. Int. J. Mass Spectrom. Ion Processes 1996, 156, 109-131.

14. Blanksby, S. J.; Ellison, G. B. Bond Dissociation Energies of Organic Molecules. Acc. Chem. Res. 2003, 36, 255-263.

15. De Turi, V. F.; Ervin, K. M. Competitive Threshold Collision-Induced Dissociation: Gas Phase Acidities and Bond Dissociation Energies for a Series of Alcohols. J. Phys. Chem. A 1999, 103, 6911-6920.

16. Gomes, J. R. B.; da Silva, M. D. M. C. R.; da Silva, M. A. V. R. Solvent and Structural Effects in the N-H Bond Homolytic Dissociation Energy. J. Phys. Chem. 2004, 108, 2119-2130.

17. Fattahi, A.; Kass, S. R.; Liebman, J. F.; Matos, M. A. R.; Miranda, M. S. Morais, V. M. F. The Enthalpies of Formation of $\mathrm{o}^{-}, \mathrm{m}-$, and $\mathrm{p}-$ Benzoquinone: Gas-Phase Ion Energetics, Combustion Calorimetry, and Quantum Chemical Computations Combined. J. Am. Chem. Soc. 2005, 127, 6116-6122.

18. Travers, M. T.; Cowles, D. C.; P., C. E.; Ellison, G. B. Photoelectron Spectroscopy of the Phenylnitrene Anion. J. Am. Chem. Soc. 1992, 114, 8699.

19. Drzaic, P. S.; Brauman, J. I. Electron Photodetachment from Phenylnitrene, Anilide, and Benzyl anions. Electron Affinities of the Anilino- and Benzyl Radicals and Phenyl Nitrene. J. Phys. Chem. 1984, 88, 5285-5290.

20. Jackson, R. L.; Pellerite, M. J.; Brauman, J. I. Photodetachment of the Azide Anion in the Gas Phase. Electron Affinity of the Azide Radical. J. Am. Chem. Soc. 1981, 103, 1802-1805.

21. McDonald, R. N.; Chowdhury, A. K. Identification of Nucleophilic 1,2and 1,4-Addition Processes with $\alpha, \beta$-Unsaturated Molecules in the Gas Phase. J. Am. Chem. Soc. 1980, 102, 6146-6147.

22. McDonald, R. N.; Chowdhury, A. K. Gas-Phase Nucleophilic. Addition Reactions of Phenylnitrene Anion Radical with Certain CarbonylContaining Molecules. J. Am. Chem. Soc. 1981, 103, 674-676.

23. McDonald, R. N.; Chowdhury, A. K. Gas-Phase Ion-Molecule Reactions of Phenylnitrene Anion Radical with Certain $\alpha, \beta$-Unsaturated Molecules: A Study of 1,2- and 1,4-Addition Mechanism. J. Phys. Chem. 1982, 1982, 3641-3645.

24. Pellerite, M. J.; Brauman, J. I. Gas-Phase Ion-Molecule Reactions of Phenylnitrene Anion. J. Am. Chem. Soc. 1981, 103, 676-677. 